Check for updates

Cite this: Soft Matter, 2021, 17,5633

DOI: $10.1039 / \mathrm{d} 1 \mathrm{sm} 90100 \mathrm{a}$

rsc.li/soft-matter-journal

\section{Correction: Exploring secondary interactions and the role of temperature in moisture-contaminated polymer networks through molecular simulations}

\author{
Rishabh D. Guha, ${ }^{a}$ Ogheneovo Idolor, ${ }^{a}$ Katherine Berkowitz, ${ }^{a}$ Melissa Pasquinellib \\ and Landon R. Grace*a
}

Correction for 'Exploring secondary interactions and the role of temperature in moisture-contaminated polymer networks through molecular simulations' by Rishabh D. Guha et al., Soft Matter, 2021, 17. 2942-2956, DOI: 10.1039/DOSM02009E.

In the original paper, the citations for references $9,10,18,33$ and 34 are formatted incorrectly. The correct citations are as shown below:

9. O. Idolor, R. Guha and L. Grace, A dielectric resonant cavity method for monitoring of damage progression in moisturecontaminated composites, American Society for Composites-Thirty-Third Technical Conference, 2018, DOI: 10.12783/asc33/ 25963.

10. K. Berkowitz, O. Idolor, M. Pankow, et al., Combined effects of impact damage and moisture exposure on composite radome dielectric properties, SAMPE Long Beach 2018 Conference and Exhibition, 2018.

18. O. Idolor, R. Guha, L. Bilich, et al., 2-Dimensional Mapping of Damage in Moisture Contaminated Polymer Composites Using Dielectric Properties, American Society for Composites-Thirty-Fourth Technical Conference, 2019, DOI: 10.12783/asc34/ 31312.

33. O. Idolor, R. Guha, K. Berkowitz, et al., Damage Detection in Polymer Matrix Composites by Analysis of Polymer-Water Interactions using Near-Infrared Spectroscopy, Proceedings of the American Society for Composites-Thirty-Fifth Technical Conference, 2020, DOI: 10.12783/asc35/34874.

34. R. D. Guha, O. Idolor and L. Grace, Molecular Dynamics (MD) Simulation of a Polymer Composite Matrix with Varying Degree of Moisture: Investigation of Secondary Bonding Interactions, American Society for Composites-Thirty-Fourth Technical Conference, 2019, DOI: 10.12783/asc34/31367.

The Royal Society of Chemistry apologises for these errors and any consequent inconvenience to authors and readers.

\footnotetext{
${ }^{a}$ Department of Mechanical and Aerospace Engineering, North Carolina State University, Engineering Building-III, 911 Oval Drive, Raleigh, NC-27695, USA. E-mail: lgrace2@ncsu.edu

${ }^{b}$ Department of Forest Biomaterials, College of Natural Resources, North Carolina State University, Biltmore Hall, 2820 Faucette Drive, Raleigh, NC-27606, USA
} 